\title{
Planning for closure - predicting mine site post-closure water quality within a Natura 2000 protection area in northern Scandinavia
}

\author{
A. Barnes SRK Consulting (UK) Ltd, UK \\ S. Johnson SRK Consulting (UK) Ltd, UK \\ M. Stewart Kaya Consulting, UK
}

\begin{abstract}
Geochemical mixing models have been developed to simulate the post-closure water quality at a mine site in northern Scandinavia. Rivers in the vicinity of the site are a known habitat for the endangered sea trout (Salmo truter) and are within a Natura 2000 protection area under the 1992 EU Habitats Directive.

Waste rock dump (WRD) seepage has been characterised though static and kinetic testwork of samples of fresh waste materials and weathered waste materials collected from existing WRDs and from multi-depth sampling from two existing pit lakes on-site. Samples collected from the existing WRD on-site show that there has been depletion of neutralising minerals within the material and that acidic conditions are developing within the dump. It is likely that WRDs are net-acid generating, and therefore suitable mitigation/treatment measures will be required in order to minimise acid production to acceptable levels.
\end{abstract}

The mine site layout has been designed such that all seepage from potentially acid WRDs is captured by pit dewatering and subsequently treated together with seepage from pit high wall. On cessation of mining, WRD seepage will continue to flow into the pit voids after groundwater levels have fully recovered, forming a point source rather than an uncontrolled diffuse source of seepage, which will aid post-closure mitigation and seepage control.

There is predicted to be both groundwater and surface water discharge from the pit lakes, therefore treatment of pit lake discharge will be required to ensure discharge limits are achieved. Potential mitigation strategies include passive treatment through a wetland system or addition of chemical ameliorant directly to the pit lake for $\mathrm{pH}$ correction. Alternatively, loadings may be reduced at the source (WRD) by addition of a neutralising ameliorant (e.g. limestone) to attenuate acidity or by the application of a low-permeability, oxygen-limiting cover to the WRD to decrease metals load.

Baseline water quality in the area is good with the exception of one watercourse that is negatively affected by uncontrolled releases of surface water from a historical tailings pond; water quality improves downstream of the tailings facility. During operations the tailings facility will be expanded. Water from the tailings ponds will be pumped away from the site, and surface water releases will cease. It is predicted that surface water quality in the immediate vicinity of the tailings facility will improve as a consequence.

Following closure of the tailings facility, groundwater seepage and uncontrolled surface water releases have the potential to raise concentrations of some parameters above baseline values. Assessment of the potential for attenuation of tailings seepage within the clarification pond through the establishment of a wetland is suggested as a potential management option for post-closure mitigation of tailings seepage.

\section{Introduction}

A hydrological impact assessment (HIA) has been undertaken for the Hannukainen iron ore-copper-gold project in northern Scandinavia (Figure 1). There is a long history of mining in the area, with the most recent activity between 1969 and 1996. Existing facilities include waste rock dumps (WRDs), open pits and 
a tailings management facility (TMF) located $11 \mathrm{~km}$ south of the mine site that contains approximately 6.6 million tonnes of tailings waste from iron, copper and gold ore processing.

It is proposed that the existing open pits be dewatered and further exploited. Waste will be segregated based on its potential to generate acidic leachates and will be disposed of within discretely segregated WRDs (see Figure 1) and streamed as follows: potentially acid forming waste (PAF), non-acid-forming rock (NAF) and overburden (OB). The TMF will be expanded to hold about $6 \mathrm{Mm}^{3}$ of high-sulphide (High-S) tailings, contained within a fully lined (base and sides) facility, and $43 \mathrm{Mm}^{3}$ of low-intensity magnetic separation (LIMS) tailings, deposited directly above the existing tailings. During mine operations, contact water will be treated where necessary and discharged to the Muonionjoki, a large regional river, via a $15 \mathrm{~km}$ pipeline.

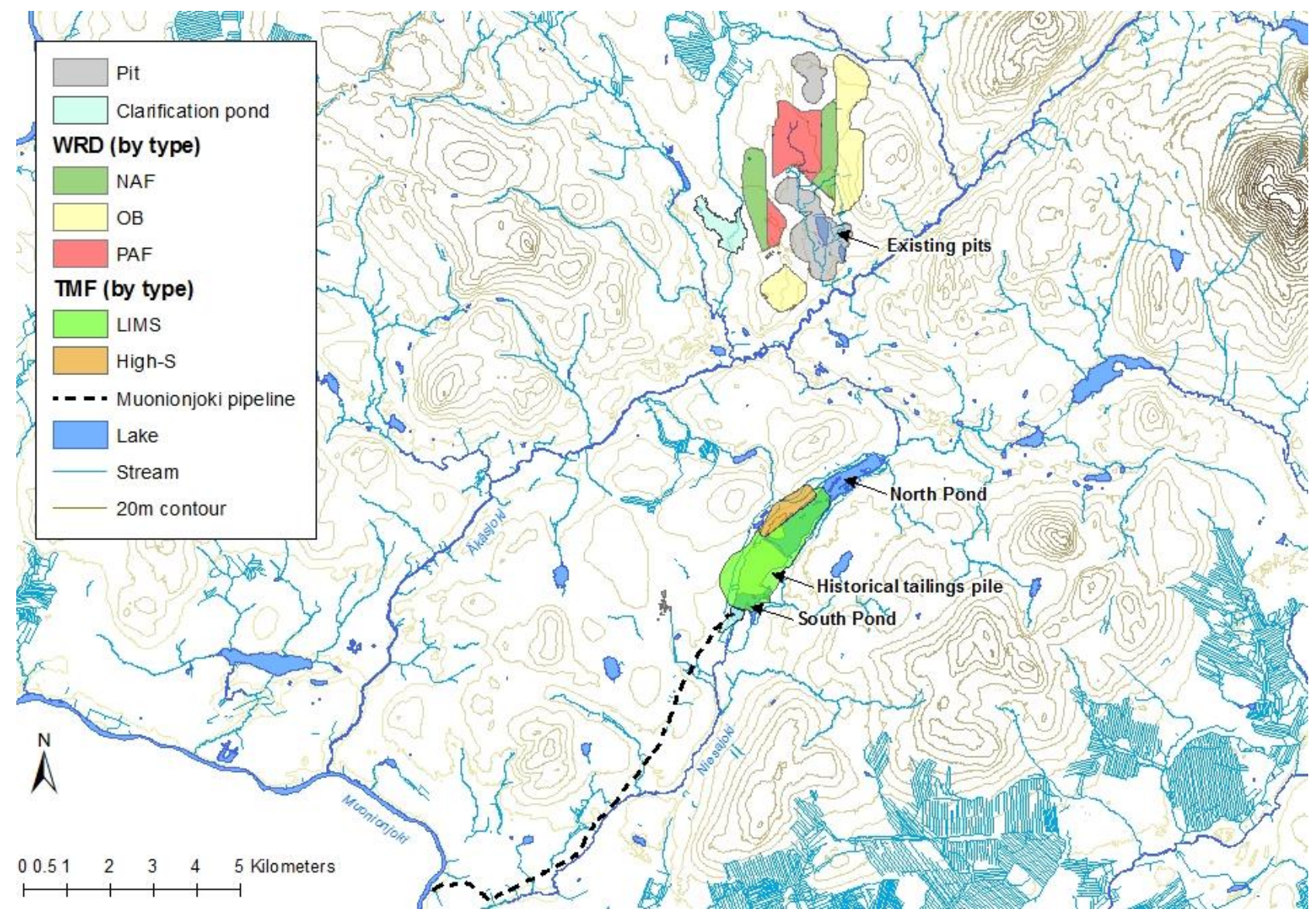

Figure 1 Proposed Hannukainen site layout

Rivers in the vicinity of the site are a known habitat for the endangered migrating sea trout (Salmo truter) and are within a Natura 2000 protection area under the 1992 EU Habitats Directive (EU, 1992). The principal receptor for the purpose of the HIA is the surface water environment. Any future mining operations must be able to demonstrate that suitable management methods can be employed to mitigate negative impacts.

\section{$2 \quad$ Methodology}

Impact management has several components: baseline characterisation, impact prediction, mitigation methods and mine design. This paper focuses on the first three components, although environmental considerations were incorporated into the mine design, for example:

- WRDs are located such that all seepage from PAF material and the majority from the NAF material is captured by pit dewatering during operations or the pit lakes post closure. 
- Expansion of an existing TMF has been selected in favour of constructing a new facility.

- The water management plan avoids any discharges of surface water to minor watercourses during operational mining.

\subsection{Water quality objective standards}

Site-specific water quality objectives (WQOs) for river water quality were developed using the ANZECC methodology (ANZECC and ARMCANZ, 2000). 'Trigger values' (TVs) and 'action values' (AVs) were derived for each chemical parameter. AVs are based on toxicological data, and if exceeded there is an expectation of immediate remedial work. Under the ANZECC method, exceedances of TVs should act as a warning of potential future exceedances of AVs. TVs are defined based on statistical analysis of baseline stream water quality data. However, at the project site baseline water quality is generally very good, and for some larger rivers the baseline data show limited seasonal and inter-annual variation, resulting in a low standard deviation within the data set. Hence, in many cases TVs were be significantly lower than AVs, and in such cases a relatively small increase in concentrations would result in an exceedance of a TV, even though the increased concentrations are not significantly above baseline or close to the relevant AV. Consequently, for this application TVs were viewed as an indicator of change from baseline conditions rather than a potential risk to aquatic life.

\subsection{Baseline characterisation}

Within the study area there are no long-term flow, or surface water level, records. Therefore baseline surface water hydrology was assessed through analysis of regional stream flow data from Finland's environmental administration OVIA database, supplemented by on-site stream flow measurements. The analysis produced estimates of annual runoff, average monthly flow conditions, low flows and wetted area for the key rivers potentially impacted by the development.

Baseline surface water quality in rivers close to the development has been characterised through a water quality monitoring program undertaken by the mine operator since May 2007. Generally samples have been collected five times per year: monthly in the summer months and once in the spring and autumn. Sampling is not possible during the winter due to freezing of the rivers.

There has been very limited groundwater monitoring at the existing TMF. A multi-level monitoring network was designed and installed as part of the HIA study and provided the majority of the baseline information. A more established monitoring network exists at the historical mine site, with piezometers installed in both the overburden and bedrock. Regular groundwater sampling and water level monitoring began in June 2011.

\subsection{Surface water flow modelling}

The combined impact on river flow, due to changes to baseflow and to surface water runoff, has been estimated for both the local and regional rivers. Changes to baseflow were generated by numerical groundwater modelling. It was assumed that the lost runoff volumes to each river were proportional to the lost catchment area. The changes in catchment area were assumed to impact stream flows in open water/non-winter months (May to October) due to decreases in surface runoff.

\subsection{Groundwater modelling}

Groundwater level data were used to calibrate a 3D numerical groundwater model of the site area, constructed using MODFLOW-2005, a block-centred, finite-difference, groundwater flow and transport model. The model was used to characterise the hydrogeological regime, including the interaction between groundwater and surface water bodies, and to estimate a water balance for the TMF ponds under different climatic conditions. 


\section{$2.5 \quad$ Geochemical modelling}

Estimates of source-term chemistry at the WRDs and TMF were determined through both geochemical mass balance calculations and thermodynamic equilibrium modelling using the USGS code PhreeqC version 2 (Parkhurst and Appelo, 2012). Source-term solution chemistry was then mixed with baseline groundwater quality, saturated minerals were allowed to precipitate and adsorption of metals to mineral phases was permitted to predict the solution chemistry discharged to the receiving watercourse.

A conservative mass balance approach was applied to predict metals concentrations within the local receiving rivers using GoldSim. This method is conservative in that it does not take into account processes such as mineral saturation, $\mathrm{pH}$ equilibrium, atmospheric gas equilibrium or attenuation through adsorption. Due to the short residence times and relatively low concentrations in the receiving watercourses, a mass balance approach is justified because it cannot be guaranteed that equilibrium will be reached or that precipitates will form a colloidal suspended load.

Upon cessation of mining the pits will be artificially flooded. Modelling incorporated a coupled mass balance-thermodynamic equilibration approach in which chemical loadings from various sources, including high wall run-off, WRD seepage and precipitation, were mixed.

\section{$3 \quad$ Baseline characterisation}

\subsection{River network}

There are marked seasonal variations in flows within rivers close to the site (Figure 2). High flows follow snow melt in spring (May and June) and low flows occur in winter (December to April), when precipitation is held within catchments as snow and ice. These seasonal variations affect the amount of natural dilution available in the river systems throughout the year.

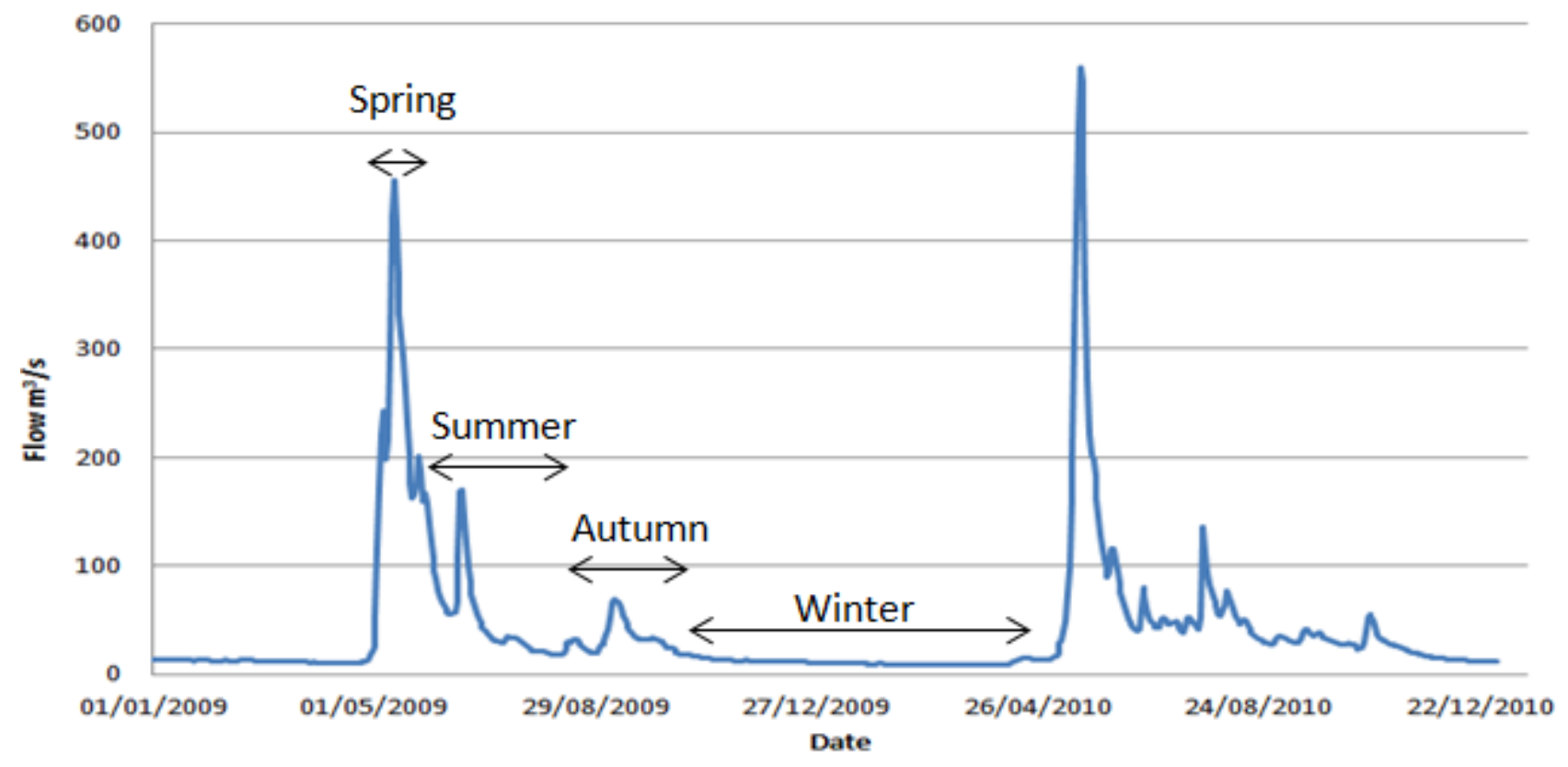

\section{Figure 2 Typical annual flow hydrograph for the site (gauge number 65761 from OIVA database)}

Water quality within most rivers is good. Baseline water quality in one local river, the Niesajoki, is negatively affected by historical tailings deposited in the existing TMF and by uncontrolled releases of surface water to the river. Water quality improves downstream of the TMF, as shown by the nickel concentrations presented in Figure 3. 

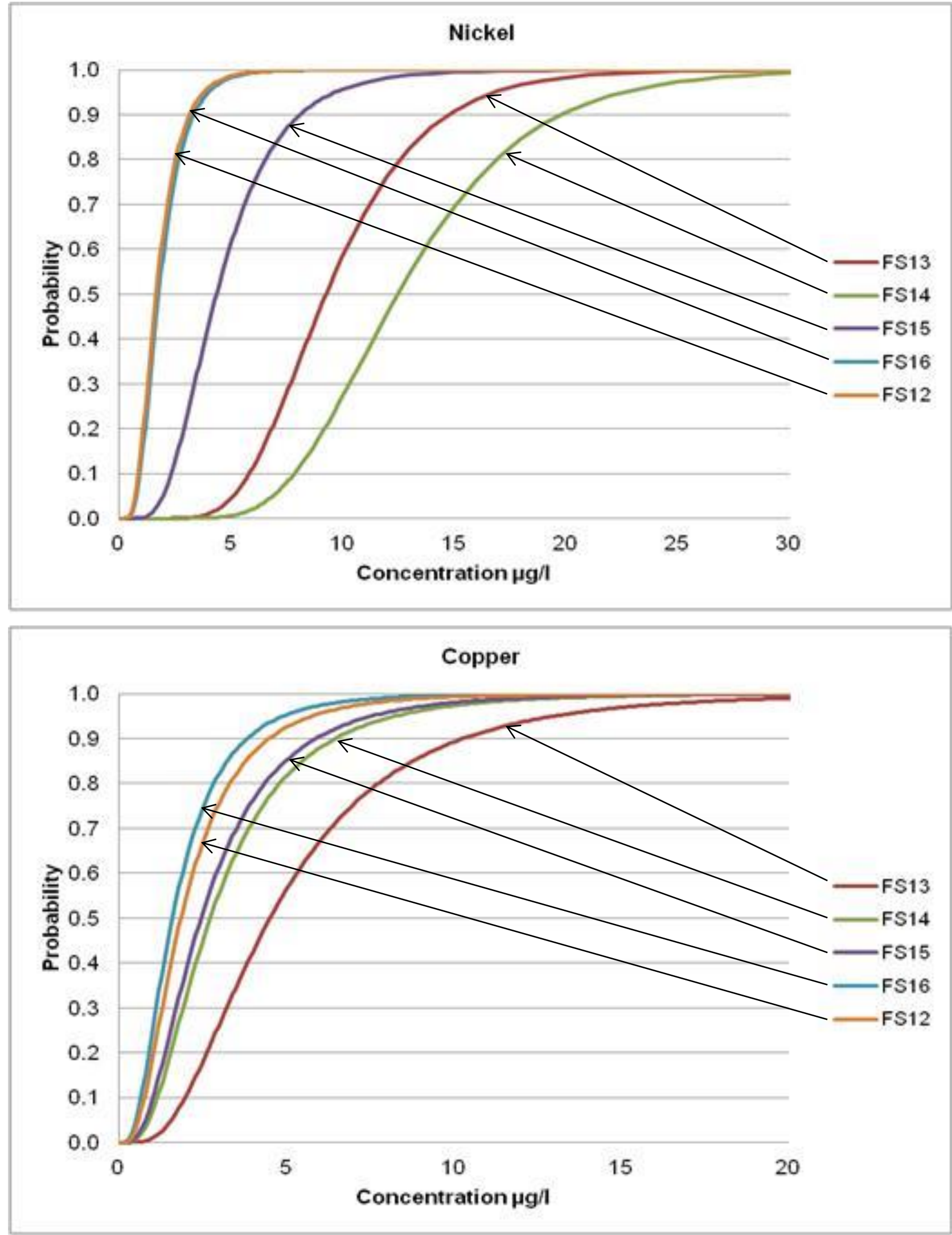

FS13=North Pond, FS14=South Pond, FS15=Niesajoki mid-point, FS16=Niesajoki close to mouth, FS12=Niesajoki at mouth

Figure 3 Water quality downstream of the existing TMF, fitted to a log-normal distribution 


\subsection{Groundwater}

Groundwater monitoring indicates that the groundwater surface is generally $0-25 \mathrm{~m}$ below ground surface throughout the project site, broadly following topography, and that the local groundwater system discharges to the wetlands and rivers, supporting base flows in these streams (Figure 4).

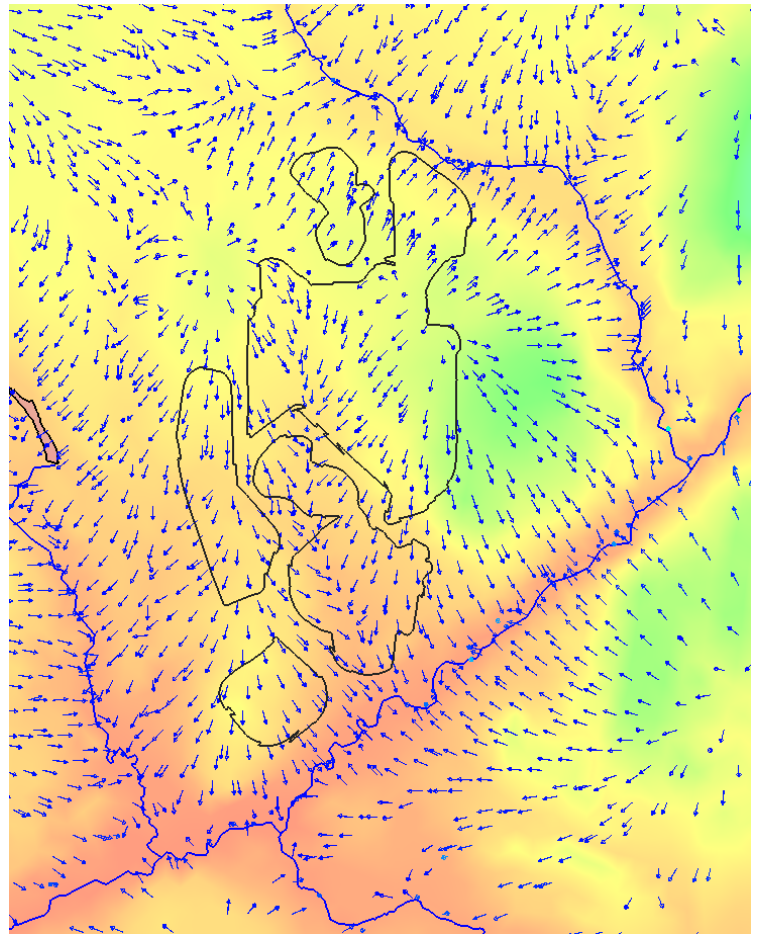

(a)

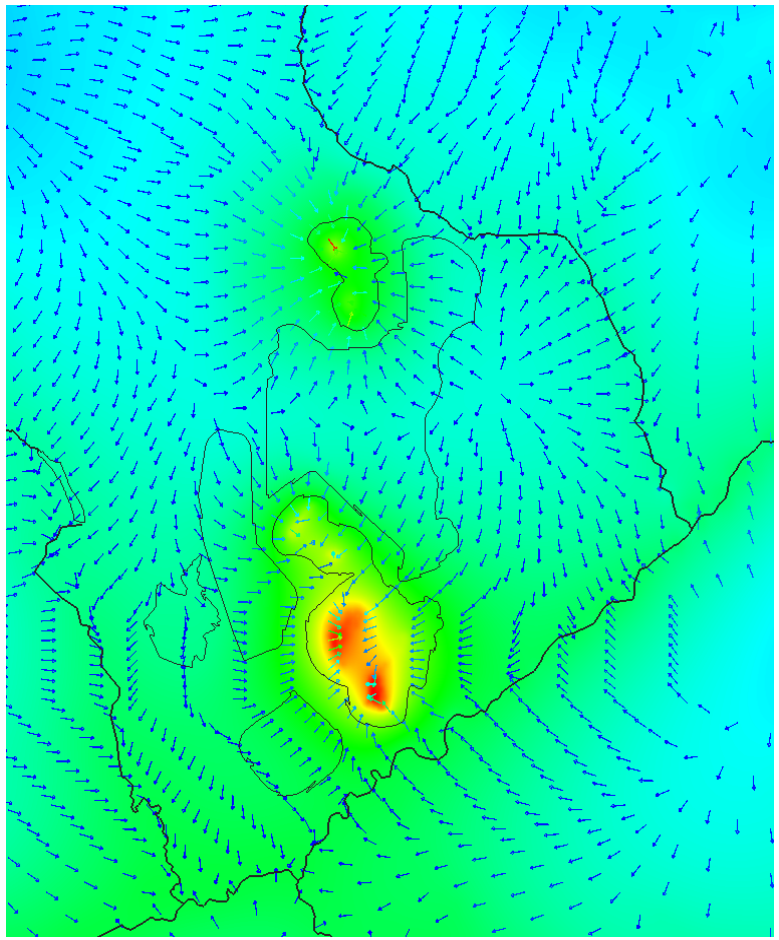

(b)

Figure 4 Groundwater contours at the mine site under; (a) baseline; and (b) life of mine conditions

The baseline water quality within the area is generally good, however there is evidence of impact from the existing WRD at the Hannukainen site and existing TMF at the Rautuvaara site, characterised by suppressed $\mathrm{pH}(<6.5)$ and elevated concentrations of sulphate, cobalt, copper and nickel in surface and groundwaters.

\section{$4 \quad$ Post-closure impact assessment}

It is predicted that pit lakes may overtop once fully recovered. There is negligible impact predicted on river flow. Calculations indicate that following the first overspill of water from the full pit lake to the rivers, TVs are predicted to be exceeded for a number of key parameters. Copper concentrations are predicted to exceed AVs under some flow conditions. Steady state predictions highlight the potential for exceedances of some AVs, with exceedance of TVs for the majority of key parameters.

Upon closure, seepage from the tailings will continue to report to the TMF ponds and local rivers. Ultimately, water from the South Pond will be discharged directly to the Niesajoki. River flow rates would be expected to return close to present-day conditions. The water quality of the Niesajoki is predicted to deteriorate due to this release, with exceedances of TVs for a number of parameters and the potential for exceedance of AVs for copper.

\section{$5 \quad$ Post-closure mitigation measures}

There is predicted to be both groundwater and surface water discharge from the pit lakes and TMF site following closure of the mine, and modelling has demonstrated potential detrimental impacts on the surrounding watercourses without adequate mitigation and management measures. Based on the current 
understanding and predictions, the following options are being considered as long-term solutions to potential water quality issues:

- Treatment of acidity in pit lakes through alkaline amendment (such as lime, $\mathrm{CaO}$ ) addition.

- Treatment of the pit lake and TMF water at point of discharge with passive wetland, permeable reactive barriers and active systems.

- Mitigation at source, for example addition of alkaline rock amendment (limestone, $\mathrm{CaCO} 3$ ) to the PAF WRD to attenuate acidity or installation of a low-permeability, oxygen-limiting cover to PAF waste to decrease metals loading to the pit lakes.

- Amending blasting strategies to ensure that waste rock fracturing is minimised.

Equally important for management methods are assessment criteria to quantify the success of mitigation. Trigger values and action criteria for changes in river flow and water quality should be refined with an aquatics expert and agreed with regulators.

It should be noted that a number of conservative assumptions have been made during water quality predictions, including full mixing of the pit lakes, no subsurface attenuation of solutes and the use of static 'NAG' testwork for prediction of WRD seepage. It is intended that water quality predictions will be updated as new information, such as fully matured kinetic test data, becomes available. In addition, adaptation of models to include post-closure mitigation strategies and limnological modelling of pit lake stratification is also planned to refine the pit lake water quality prediction.

\section{$6 \quad$ Conclusions}

This paper highlights the challenges and limitations of the methods used to predict potential post-closure impacts of mining activities. It also underlines the multidisciplinary approach that is required for a study of this kind. The study also highlights how numerical predictive modelling of prospective mine site geochemistry, hydrology and hydrogeology is essential in 'planning for mine closure', demonstrated here with the example of 'strategic waste placement' to ensure more manageable post-closure discharge.

Further numerical prediction work is being undertaken to determine the effectiveness of the prescribed mitigation measures so that, in accordance with the EU habitat directive, it can be demonstrated that any potential negative impacts posed by the mining operation can be suitably mitigated or managed prior to site development.

\section{Acknowledgements}

The authors thank SRK Consulting (UK) Limited and Kaya Consulting for their support of this submission, and Northland Mines Oy for permission to publish the findings of the study.

\section{References}

ANZECC (Australian and New Zealand Environment and Conservation Council) and ARMCANZ (Agriculture and Resource Management Council of Australia and New Zealand) (2000) Australian and New Zealand guidelines for fresh and marine water quality, National Water Quality Management Strategy, Canberra, Australia, Vol. 1, Paper No. 4.

EU (European Union) (1992) Council Directive 92/43/EEC of 21 May 1992 on the conservation of natural habitats and of wild fauna and flora.

Parkhurst, D.L. and Appelo, C.A.J. (2012) PhreeqC version 2 - a computer program for speciation, batch-reaction, one dimensional transport and inverse geochemical calculations, US Geological Survey. 
Planning for closure - predicting mine site post-closure water quality

A. Barnes et al.

within a Natura 2000 protection area in northern Scandinavia 